\title{
Contradiction Between Electric Power Market- oriented Reform and Sustainable Development: Evidence from China
}

\author{
Shuo Yin ${ }^{1, *}$, Jing Yan ${ }^{2}$, Hongkun Bai ${ }^{1}$, Jiangbo Wang ${ }^{1}$, Dawei Song ${ }^{1}$ and Junhui Liu ${ }^{1}$ \\ ${ }^{1}$ State Grid Henan Economic Research Institute, No.87 Songshan Road, Zhengzhou, China \\ ${ }^{2}$ State Grid Sanmenxia Power Supply Company, Xiaoshan Road, Sanmenxia, China \\ ${ }^{*}$ Corresponding author
}

\begin{abstract}
In this paper, by constructing a 3-phase pool game, instructions that large industrial electric power direct purchase will leads to price distortion under the condition of imperfect regulation, increase the electricity price cross-subsidy that general industrial and commercial users to large industrial users, there is regulation capture phenomenon with the electricity price structure changes. Concluded that China is now pushing to large industrial users direct purchase as a representation of electric power market reform measures can lead to conflict with sustainable development. It is not only prompted electricity price structure distorted,but also formed monopoly profits of grid enterprise in a new way. Reasonable electricity market reform should be based on the basis of sustainable development.
\end{abstract}

Keywords-market-oriented reform; monopoly profits; regulation failure; 3-phase loop game introduction

\section{INTRODUCTION}

In 2002, the State Council of China made the plan of electric power system reform. Identified electricity reform goals to break the monopoly, introducing competition and forming regional a competitive electricity market, but the effect has been bad. Christensen(1999) pointed out that how to implement effective supervision power industry especially the price regulation and supervision, is the key to improve the overall efficiency and benefit of the electric power industry. the local government as the central government agents prone to moral hazard due to decentralization, lead to local elites rentseeking, corruption ,official collusion which make the loss of total social welfare. Laffont(2002) argued that China has a hybrid structure of regulatory organizations in view of China's national conditions. It is composed of industrial session and departmental organization on the central and local level. At the same time, there is a kind of hierarchical structure between central and local regulatory department. China set up the Municipal Development and Reform Commission(MDRC) in every level of government. Similarly, also has executive in many areas agencies to assist the MDRC. The MDRC is responsible for examination and approval, put forward price adjustment scheme of small projects, while the National Development and Reform Commission(NDRC) responsible for controlling access and investment of big projects , deciding whether approve the price adjustment plan submitted by MDRC.

In this context, the meaning of direct power purchase for large user pilot which pushed by China's government in recent years is questionable. Promoting electricity market reform measures represented by the direct purchase of large user is to intensify its conflict with sustainable development in the case of resource scarcity cost cannot be reflected. Whether the electricity market promotion realize the effect of weaken monopoly profits of grid enterprises in the real sense is also the content of this paper.

The paper is organized as follows: Section 2 will show the 3 -phase pool game model while section 3 the empirical evidence. Section 4 is the conclusion of full paper.

\section{Three-Phase LOOP GAME MOdEL}

This section will build a three phase loop game model, participants of the model involve the Municipal Development and Reform Commission(represented in G),Power grid enterprises(N), large industrial users(L),General industrial and commercial users(S). Resident users(H)will be set exogenous in this model because of China's residents electricity consumption accounted for only $12 \%$ and its prices steady for a long time. This model has assumptions as follows.

\section{A. Assumptions}

Assumption1. The electricity price of a district (usually a province in China) conformity with the local guide price markup declaration system since 1996.Electricity price of large industrial and general industry and commerce formulated by MDRC and report to NDRC audit. So in this model, simplified description for MDRC has regulatory power to rule and regulation large industrial users' electricity $\left(\mathrm{E}_{\mathrm{L}}\right)$ and general commercial and industrial users' electricity price $\left(E_{S}\right)$ in the district.

Assumption2. This district has sufficient power supply. Residents of electricity consumption is $\mathrm{q}_{\mathrm{H}}$, electricity price is $\mathrm{E}_{\mathrm{H}}$ (it is exogenous in this model). Large industrial users' electricity consumption is $\mathrm{q}_{\mathrm{L}}$, electricity price is $\mathrm{E}_{\mathrm{L}}$. General commercial and industrial users' electricity consumption is $\mathrm{q}_{\mathrm{s}}$, electricity price is $E_{S}$. The final product yield of large industrial users is $\mathrm{Q}_{\mathrm{L}}$ and the final product yield of general commercial and industrial users is $\mathrm{Q}_{\mathrm{S}}$. $\mathrm{Q}_{\mathrm{L}}$ and $\mathrm{Q}_{\mathrm{S}}$ represented as follows

$$
Q_{L}=f\left(q_{L}\right) ; Q_{S}=f\left(q_{S}\right)
$$


Define $Q_{L}=q_{L}^{r_{L}}, Q_{S}=q_{S}^{r_{S}}$, and $r_{L}>>r_{S}$. Q $\mathrm{Q}_{\mathrm{L}}$ and $\mathrm{Q}_{\mathrm{S}}$ satisfy with

$$
\frac{\partial Q_{L}}{\partial q_{L}}>0 \frac{\partial Q_{S}}{\partial q_{S}}>0 \frac{\partial Q_{L}}{\partial q_{L}}>>\frac{\partial Q_{S}}{\partial q_{S}}
$$

Assumption3. The market demand of large industrial users and general industrial and commercial users faced with is not constrained, and the market price of their products is $\mathrm{P}_{\mathrm{L}}$ and $\mathrm{P}_{\mathrm{S}}$, so their profit is as follows

$$
\begin{aligned}
& \pi_{L}=P_{L} Q_{L}-E_{L} q_{L}, \\
& \pi_{S}=P_{S} Q_{S}-E_{S} q_{S}
\end{aligned}
$$

Assumption4. In the aspect of power grid, define the grid purchase price is $c(1+r)$, C is the upstream power plant generating cost assumed fixed in the model. Power grid profit is as follows

$$
\begin{gathered}
\pi_{N}=q_{H} E_{H}+q_{L} E_{L}+q_{S} E_{S}-q c(1+r), \\
q=q_{H}+q_{L}+q_{S}
\end{gathered}
$$

Assumption5. In the imperfect supervision situation, MDRC has low cost of supervision for large industrial users $\left(\mathrm{RC}_{\mathrm{L}}\right)$ and high yield $\left(\mathrm{RR}_{\mathrm{L}}\right)$,while high cost for general industrial and commercial users $\left(\mathrm{RC}_{\mathrm{S}}\right)$ and low yield $\left(\mathrm{RR}_{\mathrm{S}}\right)$.

Based on the assumptions above, the process of 3-phase loop game is as follows. In the first phrase, MDRC set the price $E_{L}$ and $E_{S}$. In the second phrase, Large industrial users determine their optimal yield $Q_{L}$ based on $E_{L}$, while general industrial and commercial users determine their optimal yield $Q_{S}$ based on $E_{S}$,then the total output of the district is $Y=Q_{L}+Q_{S}$. In the third phrase MDRC set the electricity price $E_{L}$ and $E_{S}$ for the next round according to the electric power supervision cost and revenue. The model analyzes of three situations, they are the benchmark situation which does not exist the MDRC supervision, perfect supervision situation and the imperfect supervision situation..

\section{B. Model Situations Analysis and Propositions}

1) Benchmark situation: In benchmark situation, there is no electricity price regulation, and the set of electricity price completely follow the principle of maximizing profits of power grid enterprises. So the profit of power grid is

$$
\pi_{N}=q_{H} E_{H}+q_{L} E_{L}+q_{S} E_{S}-q c(1+r)
$$

$q_{H} E_{H}$ and $c(1+r)$ is exogenous, we define $c(1+r)=c_{e}$, and after remove the impact of resident users, the model is simplified as follows

$$
\operatorname{Max}: \pi_{N}=q_{L} E_{L}+q_{S} E_{S}-c_{e}\left(q_{L}+q_{S}\right)
$$

$$
\text { s.t. } q_{L}, q_{S}, E_{L}, E_{S}>0
$$

In the same way, according to the principle of profit maximization the objective function for large industrial users and general industrial and commercial users are

$$
\begin{aligned}
& \operatorname{Max}: \pi_{L}=P_{L} Q_{L}-E_{L} q_{L}=P_{L} q_{L}^{r_{L}}-E_{L} q_{L} \\
& \operatorname{Max}: \pi_{S}=P_{S} Q_{S}-E_{S} q_{S}=P_{S} q_{S}^{r_{S}}-E_{S} q_{S}
\end{aligned}
$$

$$
\text { s.t. } q_{L}, q_{S}, E_{L}, E_{S}>0
$$

According to the backward induction, the first order derivative for (3) and (4) are as follow

Define

$$
\frac{\partial \pi_{L}}{\partial q_{L}}=r_{L} P_{L} q_{L}^{r_{L}-1}-E_{L}=0 \frac{\partial \pi_{S}}{\partial q_{S}}=r_{S} P_{S} q_{S}^{r_{S}-1}-E_{S}=0
$$

then we get

$$
q_{L}=\left(\frac{E_{L}}{r_{L} P_{L}}\right)^{\frac{1}{r_{L}-1}} q_{S}=\left(\frac{E_{S}}{r_{S} P_{S}}\right)^{\frac{1}{r_{S}-1}}
$$

Bring the results into the equation (2), we get the objective function for power grid enterprise as follows

$$
\pi_{N}=E_{L}\left(\frac{E_{L}}{r_{L} P_{L}}\right)^{\frac{1}{r_{L}-1}}+E_{S}\left(\frac{E_{S}}{r_{S} P_{S}}\right)^{\frac{1}{r_{S}-1}}-c_{e}\left[E_{L}\left(\frac{E_{L}}{r_{L} P_{L}}\right)^{\frac{1}{r_{L}-1}}+E_{S}\left(\frac{E_{S}}{r_{S} P_{S}}\right)^{\frac{1}{r_{S}-1}}\right]
$$

According to the first-order condition, we get

$$
E_{L}^{*}=\frac{c_{e}}{r_{L}}
$$




$$
E_{S}^{*}=\frac{c_{e}}{r_{S}}
$$

We have defined $r_{L}>>r_{S}$, so $E_{L}^{*}<<E_{S}^{*}$, then we get the proposition 1 in benchmark situation.

Proposition 1. Under the goal of power grid enterprise profit maximization, The MDRC tends to set low electricity price for large industrial users, while high electricity price for general industrial and commercial users, and the price is inversely proportional with the industry's electric power output elasticity.

2) Perfect supervision situation: In perfect supervision situation, the local government or MDRC regulate electricity price in order to pursue the goal of maximizing the GDP of this district. At this time the profit of power grid is $0<\pi_{0}<\pi_{\max }$. We define $\pi_{\max }$ is the maximize profits of power grid enterprises with no government controls. Now the objective function of local governments or MDRC is

$$
\operatorname{Max}: Q_{G}=Q_{L}+Q_{S}=q_{L}^{r_{L}}+q_{S}^{r_{S}}
$$

s.t.

$\pi_{N}=E_{L}\left(\frac{E_{L}}{r_{L} P_{L}}\right)^{\frac{1}{r_{L}-1}}+E_{S}\left(\frac{E_{S}}{r_{S} P_{S}}\right)^{\frac{1}{r_{S}-1}}-c_{e}\left[E_{L}\left(\frac{E_{L}}{r_{L} P_{L}}\right)^{\frac{1}{r_{L}-1}}+E_{S}\left(\frac{E_{S}}{r_{S} P_{S}}\right)^{\frac{1}{r_{S}-1}}\right] \geq \pi_{0}$

$E_{L}$ and $E_{S}$ are the price under supervision, large industrial users and general industrial and commercial users make their production decisions based on $E_{L}$ and $E_{S}$,bring $q_{L}=\left(\frac{E_{L}}{r_{L} P_{L}}\right)^{\frac{1}{r_{L}-1}}$ and $q_{S}=\left(\frac{E_{S}}{r_{S} P_{S}}\right)^{\frac{1}{r_{S}-1}}$ into equation

according to Lagrange multiplier rule we will get the objective function of local government or MDRC as follows

$$
\begin{aligned}
& M \times G=q_{L}^{i}+q_{S}^{s}+\lambda\left\{E_{L}\left(\frac{E_{L}}{r_{L} P_{L}}\right)^{\frac{1}{r_{L}-1}}+E_{S}\left(\frac{E_{S}}{r_{S} P_{S}}\right)^{\frac{1}{r_{S}-1}}-c_{e}\left[E_{L}\left(\frac{E_{L}}{r_{L} P_{L}}\right)^{\frac{1}{r^{2}-1}}+E_{S}\left(\frac{E_{S}}{r_{S} P_{S}}\right)^{\frac{1}{s-1}}-\pi_{J}\right]\right\}
\end{aligned}
$$

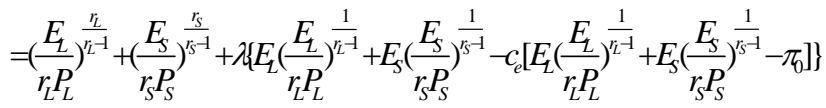

$$
\text { s.t. } 0<\lambda<1 ; q_{L}, q_{S}, E_{L}, E_{S}>0
$$

$\lambda$ is the monopoly power of grid enterprises, a bigger $\lambda$ means the stronger monopoly power of grid. To calculate the partial derivatives with respect to $E_{L}$ and $E_{S}$, according to the first-order condition, we get

$$
E_{L}^{* *}=\frac{\lambda c_{e}}{(1+\lambda) r_{L}}
$$

$$
E_{S}^{* *}=\frac{\lambda c_{e}}{(1+\lambda) r_{S}}
$$

We have defined $0<\lambda<1$, so $0<\frac{\lambda}{(1+\lambda)}<1$.It is means $E_{L}^{* *}$ 和 $E_{S}^{* *}$ are increasing functions of $\lambda$. That is to say, the electricity price received perfect supervision will increase with the monopoly power upgrade, and will decrease with the monopoly power reduce. Compared with $E_{L}^{*}$ and $E_{S}^{*}$, we will find $E_{L}^{* *}<E_{L}^{*}, E_{S}^{* *}<E_{S}^{*}$, then we get the proposition 2 as follows

Proposition 2. In perfect supervision situation, the local government or MDRC regulate electricity price in order to pursue the goal of maximizing the GDP of this district. Local governments or MDRC have an incentive to reduce the electricity price both of large industrial users and general industrial and commercial users. The regulated price will lower than the benchmark level.

On the other hand, we also find

$$
\frac{E_{S}^{* *}}{E_{L}^{* *}}=\frac{E_{S}^{*}}{E_{L}^{*}}=\frac{r_{L}}{r_{S}}
$$

Compared with benchmark level, the electricity price ratio of large industrial users and general industrial and commercial users are unchanged. That is to say, price structure remains unchanged, we get the proposition 3 as follows

Proposition 3. In perfect supervision situation, the local government or MDRC regulate electricity price in order to pursue the goal of maximizing the GDP of this district. Local government or MDRC has no incentive to change electricity price structure.

3) Imperfect supervision situation: In imperfect supervision situation, local governments or MDRC can't regulate power grid enterprises perfect, the degree of supervision depends on the balance of costs and benefits of supervision. In general, large industrial users with features of few and concentrated, thus the government or MDRC will have a small supervision cost $\left(R_{L}\right)$ and great profit $\left(R R_{L}\right)$, it is easy to supervision. Therefore the power grid enterprises have high cost to increase monopoly price of the large industrial users. On the other hand, general industrial and commercial users with features of numerous and dispersed, thus the government or MDRC will have a high supervision cost $\left(R_{S}\right)$ and low profit $\left(R_{S}\right)$, it is hard to supervision. 
Therefore the power grid enterprises have incentive to increase monopoly price of the general industrial and commercial users. We will find that from the view of government or MDRC, the net income of strengthen the supervision of large industrial users will be greater than the supervision of the general industrial and commercial users. We will get

$$
\pi R_{L}=R R_{L}-R C_{L}>\pi R_{S}=R R_{S}-R C_{S}
$$

The local government or MDRC has incentive to increase supervision for large industrial users, and to weak the monopoly power of grid for large industrial users. In this situation, Monopoly power of large industrial users $\lambda_{L}$ and general industrial and commercial users $\lambda_{S}$ would no longer same. That is to say, electricity price structure will be changed as follows

$$
\frac{E_{S}^{* * *}}{E_{L}^{* * *}}=\frac{\frac{\lambda_{S} c_{e}}{\left(1+\lambda_{S}\right) r_{S}}}{\frac{\lambda_{L} c_{e}}{\left(1+\lambda_{L}\right) r_{L}}}=\frac{\left(\lambda_{S}+\lambda_{L} \lambda_{S}\right) r_{L}}{\left(\lambda_{L}+\lambda_{L} \lambda_{S}\right) r_{S}}
$$

Compared with (13) we will find that electricity price structure will be changed when enter the next round of the game. The proportion of changes $(\mathrm{CH})$ is

$$
C H=\frac{\left(\lambda_{S}+\lambda_{L} \lambda_{S}\right)}{\left(\lambda_{L}+\lambda_{L} \lambda_{S}\right)}
$$

We have explained that $\lambda_{S}>\lambda_{L}$, so $\mathrm{CH}>1$. Then we get the proposition 4 as follows

Proposition 4. In imperfect supervision situation, the local government or MDRC has incentive to change the electricity price structure when enter the next round of the 3-phrase loop game, the net gap of electricity price between large industrial users and general industry and commerce is widening.

\section{Result and Discussion}

With the loop game, the electricity price net gap between large industrial users and general industrial and commercial users continues to widen, grid monopoly power for large industrial users will reduce, at the same time, grid monopoly power for general industrial and commercial users will increase. In the extreme case, large industrial power direct purchase will be appeared, it is means grid enterprises lose the monopoly power for large industrial users while the monopoly power for general industrial and commercial users will be increased. The result is cross subsidy degree increase and electricity price distortion constant seriously in China.

\section{CONCLUSIONS}

Reform measures of electricity market in China will lead to the process of market-oriented reform biased, as representative, large industrial users direct purchasing of electricity can demonstrate this phenomenon. As the goal of weaken the grid monopoly power to promote large industrial direct purchase of electricity will exacerbate the electricity cross subsidy between large industrial users and general industrial and commercial users. In the situation of imperfect supervision will lead to price structure distortions, and will form a new way to get monopoly profits for the power grid enterprises.

The electricity cross subsidy between large industrial users and general industrial and commercial users, to some extent, can be understood as the monopoly profits diverted the cost of sustainable development. General industrial and commercial users not only provide a large number of monopoly profits for power grid enterprises, but also pay for the extensive product mode of large industrial users. At the same time, general industrial and commercial users become the new source of monopoly profit for grid enterprises. There is certain failure phenomenon for the reform of electric power on antitrust target which making the way of economic development sustained extensive inertia in China. We conclude that reasonable power market reform should be based on sustainable development.

\section{ACKNOWLEDGMENT}

This research was supported by the Nation Natural Science Foundation of China (Linkage Grant Number: 71333007) on Research on the Mechanism and Policies of Industrial Transformation and Upgrading in Developed Regions.

\section{REFERENCES}

[1] Christensen, Edward. W. An Exploration of Industry, Culture and Revenue Growth.Organization Studies,1999,20(3),pp.397-422.

[2] Laffont, Jean-Jacques. Management of Public Utilities in China. Annals of Economic and Finance,2004,(5),PP:182-210.

[3] Shu Fan,Rob J.Hyndman. The Price Elasticity of Electricity demand in South Australia. Energy Policy 2011,(39),pp.3709-3719.

[4] Hamidreza Zareipour, Kankar Bhattacharya, Claudio A.Canizares. Electricity Market Price Volatility: the Case of Ontario. Energy Policy 2007,(35),pp.4739-4748.

[5] Hall, RE. Market Structure and Macroeconomic Fluctuations. Bookings Papers on Economic Activity,1986,(2).pp.285-338.

[6] Hall, RE. The Relation between Price and Marginal Cost in U.S. Industry, Journal of Political Economy,1988,(5) pp. 921-947.

[7] Roeger, W. Can Imperfect Competition Explain the Difference between Primal and Dual Productivity Measures? Estimates for U.S. Manufacturing. Journal of Political Economy,1995,(2).pp.316-330.

[8] Solow R. Technical Change and the Aggregate Production Function. Readings in Macroeconomics,1957,(44).pp.312-320.

[9] Harberger A C. Monopoly and Resource Allocation, The American Economic,Review,1954,(44).pp.77-87. 